Vol. XVII No. 1

\title{
Bird Houses
}

By F. G. Bard, Sask. Museum of Natural History

Instructions for building bird houses may be found in many books and pamphlets. Perhaps your library has How to build bird houses and feeders by W. E. Schultz and My hobby is bird watching by Mary $P$. Pettit. Or, you can oobtain free two pamphlets which we have used in preparing this article: Bird houses and their occupants (Wildlife Division, Dept. of Northern Affairs and Natural Resources, Ottawa) and Bird houses are fun to build (Royal Bank of Canada, Regina).* Another valuable source of information, of course, is the friend or neighbour who has already had experience in building bird houses.

A number of species of birds nesit successfully in bird houses. All of these nest as single pairs, with the exception of the Purple Martin for which a martin colony house is recommended. H. H. Mitchell (formerly with the Museum) established a colony of martins south of the Normal School in Regina. The house was occupiea for several years before being deserted, probably due to constant pressure from House Sparrows. For more than 20 years martins avoided Regina, and they have only recently returned to nest in the city. In the 30's I placed martin houses at Regina Beach and after a period of two years succeeded in having the houses occupied. At that time the closest colonies existed at Raymore about 50 miles northeast. Now they are quite common on both sides of Last Mountain Lake. A colony of martins is a fine addition to any city park, home or summer cottage. Properly constructed and located, there is no reason why martin colony houses should not be successful. Fig. 5a shows an occupied martin house situated in one of the busiest sections of Edmonton.

Many variations from the standard types of houses are possible, but one must keep in mind that good bird houses are built for birds-they should not be toy houses that imitate houses for humans! Fancy, gaudycoloured houses are less successful than the more practical, protectivelycoloured bird houses. One practical suggestion is the- $\bar{t} s \mathrm{~s}$ of asphalt roof- ing (see fig. $3 \mathrm{~b}$ ) which is very flexible. I favour this over and above some of the elaborate pitched roofs where constant problems are experienced as a result of heat and exposure to weather. Another common mistake is making the entrance too small or too close to the floor. Remember that in nesting sites provided by the carpenter birds, the woodpeckers, we often find Trec S.wallows using an entrance as high as 10 inches from the floor. Another important factor is ease of cleaning, so that the house can be made attractive for ntxit spring's occupant.

Sometimes special problems must be faced. One year we found that our Tree Swallows had no success in a standard house. When the house was cleaned in the fall we found five dead swallows. Presumably House Sparrows had attempted to take over the house, but not being able to get in, had worried and actually killed the female swallows. Next year we provided additional entrances so that the Tree Swallows could escape attack.

Another special problem was met by using wooden nail kegs to reha:bilitate the uncommon Goldeneye duck along Last Mountain Lake. In 1952, the Department of Natural Resources, the Museum, and a youth group (now disbanded) under the leadership of Al Copeman of Regina co-operated in this experiment. The nest barrels were painted in camouflage colours, numbered, and installed in the trees along the lakeshore to replace natural nesting sites in old dead trees washed away during the years of high water. The story was carried in the Blue Jay (Vol. XII, No. 2, June, 1954). The project was successful; Goldeneyes increased. Some neists were actually found to have two females. The results of this project were rewarding, and we feel that it should be tried again.

A very useful type of house is the shelter type, consisting simply of a floor with a railing around it to support the nest and a roof over it. At Regina Beach I found that kingbirds, Mourning Doves and robins used this type, and that when it was placed under the eaves it was acceptable to the phoebe. 

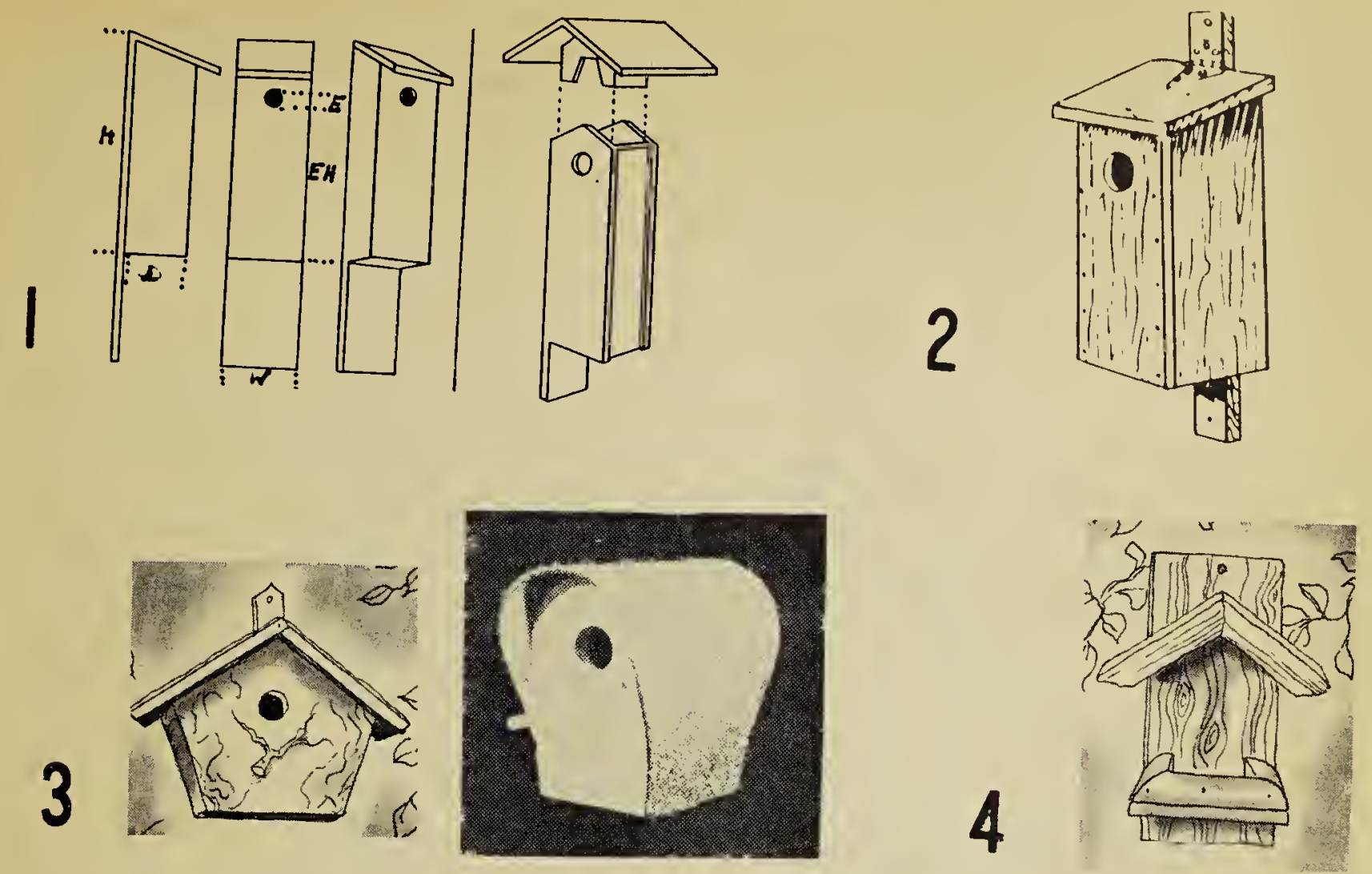

BIRD HOUSE DIHENSIONS

BIRD HOUSE DIMENSIONS

W. D. H. E. EH.

1. Tree Swallow $659911 / 27$

2. Bluebird $65911 / 27$

3. House Wren $5581^{*} 6$

4. Robin 669

5. Martin 66624

*More exactly 15/16" - the size of a 25c coin.

NOTE - Dimensions given for bird houses vary a great deal. The above dimensions are ones which have proved satisfactory.
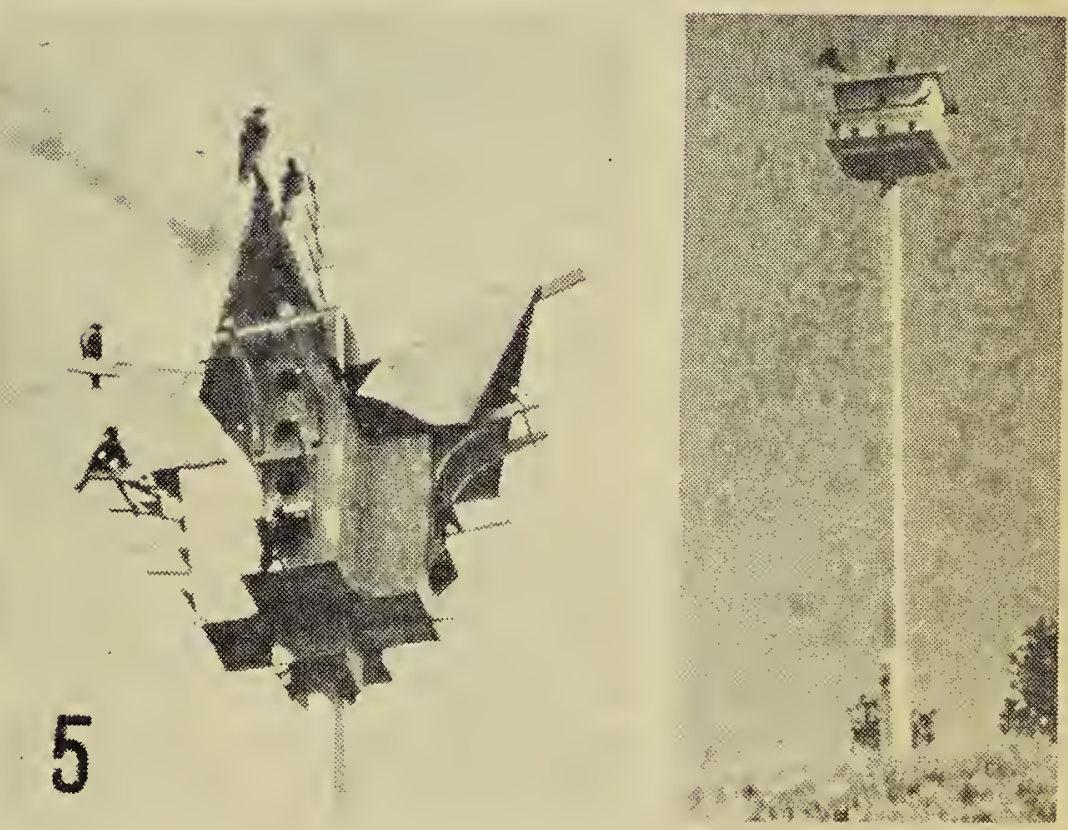

To establish birds successfully one must be patient, for it may be several seasons before you get results. The bird house itself is not the only consideration - an adequate supply of shrubs and trees is needed to provide shelter and food. Difficulties can be expected if House Sparrows and cats have free access. Because of territorial demands, some problems arise as a result of encouraging more birds than would normally live in any given area. These problems, however, are not serious enough to keep us from attracting birds to live near our city homes and summer coittages.

If you have good practical information concerning the construction

and maintenance of bird houses or good illustrations, we should' like to hear from you. With the receipt of worthwhile material another article can be prepared next season.

\section{PHOTO SHOW}

To encourage public interest in natural history preliminary to the A.O.U. meeting, the Museum is having a gigantic photo exhibition of 200 black-and-white photos from its files, Birds Through the Year, at the Norman Mackenzie Art Gallery. This will be open Felb. 19-March 15. Be sure to see it. 